\title{
Constructive Suggestions on the Development of Leisure Sports Industry in Ganzhou \\ Renzhuo Zhang
}

\author{
School of Science, Jiangxi University of Science and Technology, Ganzhou, China \\ 47605591@qq.com
}

Keywords: Ganzhou; Leisure sports; Industry; Suggestion

\begin{abstract}
This article studies the current situation of leisure sports industry in Ganzhou by using literature consultation, interview method and field research method. And through relevant researches on the current situation, problems existing in the development of leisure sports industry had been found, and thus corresponding suggestions were proposed: create good leisure sports environment to attract tourists from various places and promote further development of this industry; then enhance propaganda, and establish scientific leisure sports values, the development of leisure sports should be connected with the nationwide fitness campaign tightly; the school should establish new educational philosophy; pay more attention on cultivating social sports instructors, popularize red sports to boost the development of leisure sports industry.
\end{abstract}

\section{Introduction}

Leisure time is an inevitable rules for social development, "the coming of the leisure time" would provide opportunity for the development of leisure sports development, and as a cultural, scientific and healthy ways of life, it could help people gain spiritual motivations for life at the same time of promoting healthy development of both the body and the mind, it plays an important role in increasing the overall quality of people; also, has significant effect on promoting the development of industrial economy and the society and interpersonal communication, the vitality of the sports cause and the perfection of the life-long education system. The leisure sport has become a way of life and the trend of times. While the development of the leisure sports industry was still in a low level, such as the fitness and leisure industry, sports performance industry and the intermediary service of sports in the sports noumenon industry. Rapid development of the leisure sports industry is a new way of accelerating the economic development and enlarging economic aggregate, also is an enforcement point to ensure people's well-beings, promote employment and increasing people's health and life standard, it also has practical significance in increasing the vitality of sports development and serve the social development of Ganzhou.

\section{Overview of the Leisure Sports Industry}

According to the general definition of leisure sports industry in foreign countries and the standard in National Cultural Reform and Development Outlines during the "twelfth five-year" Period, the determination of the leisure sports industry is as follows: the sports leisure industry covers all the supports and services for the leisure sports provided by all works of the society, and all the production and operating activities generated from those services. That is the leisure sports industry is the general term for all the supports and services provided by all works of the society and all the production and operating activities generated from those services. The main industry of the leisure sports industry refers to the one which directly provides products and services of leisure sports activities, the related industry refers to the industry which indirectly provides products and services. Namely main industries such as the fitness and leisure industry, sports performance industry, the lottery industry, leisure sports service industry, sport tourism industry, sports media industry and 
E-sports industry, and related industries such as sports construction industry, leisure sports economic industry, leisure sports trade industry and so on.

\section{Main Problems during the Development of Leisure Sports Industry in Ganzhou}

Lack of Management Troops for the Sports Industry. Currently, the professional management troops in the leisure sports industry in Ganzhou is relatively weak, there is lack of decision-making talents, managerial talents and professional service talents. Most of the existing managers are retired athletes, trainers and personnel without any professional knowledge. Though they are familiar with sports, they have little knowledge about market operation and the economy, and are in lack of sale knowledge and techniques, thus they could not market sports products and services well, nor effectively give play to sports industrialization market mechanism. On the other hand, some investors and operators are familiar with the business management, but are in lack of knowledge for the sports industry, and do not know enough about the sports products, and the characteristics and rules of the market, thus they could not integrate sports with the market. For lack of marketing consciousness and professional talents, the marketing strategies of most operating units of leisure sports are relatively lagged behind, and are in lack of advanced ideas such as humanistic and green marketing which could better satisfy the demand of customers and occupy the market.

Disordered Development of the Leisure Sports Industry Development. The development of leisure sports industry in Ganzhou is still at the initial stage, the governance mechanism was unsound, and therefore, the development is disordered. It mainly demonstrated in the following aspects: (1) the operation sectors of leisure sports industry is not less on the amount, while the price is high, few of those places apply to the mass population. (2)for lack of professional industrial management and macro-control of the investors, most of the leisure projects are repetitive, and lack of individuality and creation, the overall distribution is unreasonable, mostly are concentrated at flourishing areas, while few locate at surrounding counties and newly built communities. (3)the lack of industrial management control has led to serious repetition in the projects setting, and short of creation.

Uncoordinated Business System Development, Weak Overall Profitability Capacity of Enterprises. Leisure sports industry is a mutually complementary system engineering which covers many systems such as education, medicine, transportation, business, tourism, culture and safety. The rapid development could only be realized through coordinated development of all departments. The problems in the uncoordinated development among all systems, such as traffic congestion, catering mess, unmatched accommodation and poor service during leisure sports consumption, have not been solved. Presently, the leisure sports industry in Ganzhou basically belongs to low-profit industry, the overall profitability capacity of the sports fitness enterprises is weak. Many operators think that, the profit of leisure sports industry is much lower than that of the wholesale and retail sale trades and the catering industry. As known from survey, the sports consumption level in Ganzhou is mainly restrained by the income level, the citizen now could only afford relative lower price, and the profit margin of sports fitness enterprises is still small.

The Content of the Sports Tourism Industry is too single to Represent Regional Characteristics. The development of the sports tourism industry is rapid, but still at the initial stage, mainly includes economic sports tourism. The bearing ability of people is limited, and the overall consumption level is relatively lower, which directly causes the relative shortage in the demand of sports tourism market. And the content of tourism is single and simple, the existing projects for participation and appreciation of tourists are in lack of creation, and could not sufficiently represent the characteristics of old revolutionary base areas. Without enough investment, the abundant tourism resources could not be developed effectively, and existing tourism products could not be packed well, the propaganda of sports tourism are simple in content, old in form and single in channel, therefore, the influence to the outside was small, and there is no obvious effect. Added with the fact that people's recognitions on sports tourism consumption which could directly influence the sports 
tourism consumption are low, and the strength of the consumption could directly influence the effect of the sports tourism consumption, the type of sports tourism consumption and the consumption degree, and further influence the development of the sports tourism development.

The Current Situation of the Sports Fitness Industry. At present, the body-building and recreation market has been grown rapidly in our country, the market structure with a variety of investment subjects, and sports products of high, middle and low level competing with each other has been formed, also, it is playing a more and more important role in stimulating domestic demand and enlarging employment. Though the development of body building and recreation market in Ganzhou is relatively later than developed regions, compared with development of other sports market in Jiangxi Province, the body building and recreation market is still very mature. Right now, there are several large-scale gymnasiums, as well as many fitness centers such as Yoga rooms and dance studios in Ganzhou, which could basically meet the fitness demand of citizens in Ganzhou, while problems such as unclear management philosophy, lack of long term plans and being involved in vicious competitions still exist.

\section{Suggestions on the Development of Leisure Sports Industry in Ganzhou}

Improve Public Sports Venues Construction Plan, Carry out Construction of Sports Venues well. List the construction of sports venues and facilities in the urban and rural construction plan of city, county and village level, the general plan for land use as well as "the thirteenth five-year" major construction project investment plan of governments of all levels. Implement specifications, standards and land quota for public sports facilities construction, improve the service efficiency of public sports facilities. Relevant departments of the government should give support and concessions for the project proposal, land expropriation and fee remission of sports venues and facilities construction. Accelerate the construction of public sports facilities in central cities, optimize investment mode of public sports facilities construction and try to make the construction of sports venues and facilities benefit more people. Make full use of the resources of the town squares, parks, newly built residential districts and universities and colleges, strive to form a "point, line and surface" three dimensional sports facilities network such as fitness corridor, fitness square, fitness community, fitness Greenland and fitness school.

Cultivate Good Environment to Promote the Development of Leisure Sports Industry. Some suggestions on the revitalization of Soviet areas provided policy support for the national feedback to old revolutionary base areas. Particularly the mechanism of counterpart assistance to especially difficult counties such as the 18 counties in Ganzhou from the central state organ, and the policy of encouraging the central state organ to establish cadre education training base in Ruijin, all of them have provided hard-won opportunities for the development of leisure sports industry in Ganzhou. Relevant departments of Ganzhou should carefully implement the requirement of building "creative, livable, safe, ecological and happy Ganzhou", welcome tourists from all the world to experience the revolutionary feelings, appreciate Hakka customs and enjoy the achievement of the old revolutionary base areas, and thus with this as an opportunity, promote the development of leisure sports industry in Ganzhou.

Enhance the Propaganda, Establish Scientific Leisure Sports Values. Government departments at all levels should perform their functions, and continue to enhance propaganda of leisure sports through various means such as newspaper, advertisement, internet, TVs and health lectures, which could encourage people to actively take part in various fitness leisure sports, and guide people to establish scientific and healthy view on leisure sports, and help people realize that leisure sports is an inevitable mean and method to keep the health of the body and mind and overall development under the pressure of high speed and high efficiency work.

Vigorously Cultivate Social Instructors for Leisure Sports. With the rapid development of leisure sports, it is needed to further strengthen the work of social sports instructors, improve their 
professional knowledge and quality, so as to play an important role in the development of mass sports, and get along with the project of national fitness, and this would bring challenge and opportunity for sports workers. Exchanges and cooperation between sports and the economy should also be widely carried out, so as to cultivate inter-disciplinary management personnel who have knowledge on both sports and economy in multiple channels; enhance occupational training on the employees in the sport service industry, so as to improve their quality.

Sing the Main Melody of Red Sports, Promote the Development of Leisure Sports. Red sport is unique in the world, there are no such sports in other countries, and the red tourism is also valuable sports resources for regions south of Ganzhou. The purpose of sports in south of Ganzhou is quite clear, instead of simple sports, they are combination of exercising, preparing for the war and recreation, many of those red sports item are the predecessor of contemporary leisure sports. The leisure of red sports is mainly represented in developing and promoting games, endow traditional games with new meaning, and make the sports gain mass and wide adaptability. The development of leisure sports needs to emulate the red sports spirit, combine the development of leisure sports with people's life, work and the geological condition in regions south of Ganzhou. The basic subjects, themes, missions and experience involved in the red sports have profound effect on the modern value of leisure sports industry which could not be ignored. The establishment of red sports meeting provides a good carrier for the inheriting and carrying forward of red sports spirit, and this would promote the development of leisure sports industry in Ganzhou.

\section{Conclusions}

The rapid economic development brings people unceasingly increased material conditions and more leisure time, which have laid a solid foundation for the development of leisure sports industry. In the future, the development of leisure sports industry in Ganzhou should grasp the opportunity for development, start from the real conditions of Ganzhou, and further guide the consumption idea of citizens, so as to form a healthy view on leisure. The government also should accelerate the issue of relevant policies and measures to further standard the market of leisure sports. All enterprises should renew the operational ideas, develop more marketing mix, so as to be more competitive and increase the operation benefit. All links of the society should fulfill each other's duty, thus to promote the healthier, faster and better development of the leisure sports industry in Ganzhou.

\section{References}

[1] H.N.Zhan, Connotation Analysis on Leisure Sports. Journal of Physical Education, (2011) No.5. (In Chinese).

[2] Y.L.Zhen, Research on the Shacklesfor Leisure Sports Development under the Background of Strong Country in Competitive Sports. Theoretical Observation, (2013)No.9. (In Chinese).

[3] S.Zhang, Research on the Core Concept and Policies of Leisure Sports Industry in our Country. Sports Science Research, (2013)No.5.(In Chinese).

[4] Y.L.Yang, Research on the Current Situation and Strategies of Leisure Sports Industry in Sichuan Province. Contemporary Sports Technology, (2014)No.36. (In Chinese).

[5] Jiangxi Province "11th five-year" Plan for National Economic and Social Development. 2006.(In Chinese).

[6] J.Y.Liu, Research on the Development of Leisure Economy in China. Xiamen University, 2007. (In Chinese).

[7] Z.X.Pan, Research on the Development of Leisure Sports Industry in Western China. Modern Science and Technology Information, (2014)No.2. (In Chinese). 
[8] Y.K.Zhang, N.Wang and L.S.Yang, Research on the Development of Leisure Sports of our Country at Present Stage. Journal of Chengdu Sport University, (2002)No.4.(In Chinese).

[9] Z.Q.Jin, Industry Characteristics Analysis on Leisure Sports Industry. Journal of Xi an Institute of Physical Education, (2006)No.23. (In Chinese).

[10] H.Tian and H.Zhou, Leisure Sports and its Development in China. Sports Science, 2006. (In Chinese).

[11] X.L.Gong. Leisure Sports. Hunan Normal University Press,(2007)No.4. (In Chinese).

[12] B.Zhou and Q.Zhao, Leisure Sports. Guangxi Normal University Press, 2001.6. (In Chinese).

[13]Determination of CPC Jiangxi Provincial Government, and Jiangxi Province People's Government on the Further Development of Sports Causes, 2003.(In Chinese). 